Abstract-Estimates of abundance of the American lobster (Homarus americanus) are often based on catch data and are, therefore, potentially influenced by trap saturation (a plateau in catch levels over time). Although aspects of trap saturation in standard lobster traps have been investigated, less is known about the process of saturation in ventless traps that are currently used for stock assessments. Our goal was to investigate the possible mechanisms leading to trap saturation in ventless and standard lobster traps, by using in situ time-lapse video surveillance. The dynamics of saturation in standard traps were difficult to assess in this study because entry and escape rates were similar throughout each trial, under the conditions tested; therefore, few lobsters accumulated in the standard traps. In contrast, few lobsters escaped from ventless traps used under the same conditions. Lobsters consistently accumulated in ventless traps during the first day of fishing, and then the catch plateaued on the second day as fewer lobsters entered those traps. On the second day of soaking, catch apparently reached a dynamic equilibrium in which the rate of entry declined to the point where it was equal to the rate of escape.

Manuscript submitted 22 May 2017. Manuscript accepted 19 January 2018. Fish. Bull. 116:161-170 (2018).

Online publication date: 13 February 2018. doi: $10.7755 / F B .116 .2 .5$

The views and opinions expressed or implied in this article are those of the author (or authors) and do not necessarily reflect the position of the National Marine Fisheries Service, NOAA.

\section{Underwater video surveillance of American lobsters (Homarus americanus) to understand saturation levels in lobster traps}

\author{
Abigail S. Clark (contact author) $)^{1,2}$ \\ Steven H. Jury ${ }^{3}$ \\ Jason S. Goldstein ${ }^{1,4}$ \\ Thomas G. Langley ${ }^{1}$ \\ Winsor H. Watson III ${ }^{1}$ \\ Email address for contact author: aclark@mote.org \\ 1 Department of Biological Sciences and \\ School of Marine Sciences and Ocean Engineering \\ University of New Hampshire \\ 46 College Road \\ Durham, New Hampshire 03824 \\ 2 Program in Fisheries and Aquatic Sciences \\ School of Forest Resources and Conservation \\ University of Florida \\ 7922 NW $71^{\text {st }}$ Street \\ Gainesville, Florida 32653 \\ Present address for contact author: The Elizabeth Moore International Center for Coral Reef \\ Research \& Restoration \\ Mote Marine Laboratory \\ 24244 Overseas Highway \\ Summerland Key, Florida 33042 \\ Department of Biology \\ Saint Joseph's College \\ 278 Whites Bridge Road \\ Standish, Maine 04084 \\ 342 Laudholm Farm Road \\ Wells, Maine 04090
}

Effective monitoring is important for successful management of fish and shellfish populations, especially given the impacts of overfishing and a changing ocean climate (Brander, 2010). Catch per unit of effort (CPUE) is currently the most widely used indicator of abundance for the American lobster (Homarus americanus), which is the focus of one of the most valuable fisheries in the United States and Canada. Furthermore, CPUE is an important metric for stock assessments. However, owing to concerns that catch in traps may not provide an accurate index of actual populations under certain conditions (Watson and Jury, 2013), several U.S. states (Maine, New Hampshire, Rhode Island, and Massachusetts) now conduct annual surveys with ventless traps to better es- timate relative abundances of American lobsters (MDMR ${ }^{1}$; $\mathrm{MADMF}^{2}$ ).

Determining indicators and reference points for American lobster abundance, particularly those of prerecruits, remains an ongoing challenge (Caddy, 2004; Steneck, 2006). Jury et al. (2001) showed that approximately $94 \%$ of American lobsters that entered standard traps ultimately escaped and, of those that escaped, $28 \%$ exited through the es-

\footnotetext{
${ }^{1}$ MDMR (Maine Department of Marine Resources). 2011. Maine Department of Marine Resources 2011-2012 research plan, 27 p. [Available from website, accessed January 2017.]

2 MADMF (Massachusetts Division of Marine Fisheries). 2014. Massachusetts Division of Marine Fisheries 2014 annual report. [Available from website, accessed January 2017.]
} 


\section{Table 1}

Summary of the 6 trials in which a video surveillance system attached to lobster traps was used to investigate trap saturation in ventless ( 3 trials) and standard traps ( 3 trials) deployed off New Hampshire (Wallis Sands) during 2010-2012. The total number of hours of recorded video excludes nighttime footage because the lobster-trap video system recorded behavior of American lobsters (Homarus americanus) only during the day ( 0900-1700 or $1900 \mathrm{~h})$. Density represents the number of lobsters on the bottom during each trial. The final catch values in traps were calculated on the basis of the number of entries and escapes observed in videos.

\begin{tabular}{lllcccc}
\hline Trial & Trap type & Start date & End date & $\begin{array}{c}\text { Total hours } \\
\text { recorded }\end{array}$ & $\begin{array}{c}\text { Density } \\
\left.\text { (individuals } / \mathrm{m}^{2}\right)\end{array}$ & $\begin{array}{c}\text { Final catch } \\
\text { (no. of lobsters) }\end{array}$ \\
\hline 1 & Standard & $09 / 24 / 2010$ & $09 / 25 / 2010$ & 15.8 & 0.136 & 3 \\
2 & Standard & $06 / 28 / 2011$ & $06 / 29 / 2011$ & 24.4 & 0.053 & 0 \\
3 & Standard & $07 / 18 / 2012$ & $07 / 19 / 2012$ & 19.3 & 0.054 & 1 \\
4 & Ventless & $09 / 14 / 2010$ & $09 / 15 / 2010$ & 19.5 & 0.136 & 28 \\
5 & Ventless & $08 / 06 / 2011$ & $08 / 07 / 2011$ & 15.7 & 0.100 & 27 \\
6 & Ventless & $08 / 25 / 2011$ & $08 / 26 / 2011$ & 15.3 & 0.140 & \\
\end{tabular}

cape vents in the parlor; the remaining $72 \%$ escaped from the kitchen, where the bait was located, through one of the 2 entrances. Although the exit of sublegalsize lobsters through the escape vent is advantageous for sustaining lobster populations, it is clear that catch in standard traps does not always correlate well with either the abundance or size composition of lobster populations on the bottom (Courchene and Stokesbury, 2011; Watson and Jury, 2013; Clark et al., 2015). Ventless traps, which lack escape vents (Estrella and Glenn $^{3}$ ), help to alleviate this problem and, for this reason, are being used in assessments by some state fisheries management agencies $\left(\mathrm{MADMF}^{2}\right)$.

Recently, Clark et al. (2015) showed that ventless traps provide a better representation of American lobster density and size composition than standard traps. Although the time it took for ventless traps to saturate, or reach a point where catch plateaued (16-24 h), was similar at different lobster densities surrounding the experimental traps, the maximum catch was correlated with the greatest lobster density surrounding the traps. In other words, traps saturated at a level of catch that was much less at low densities of lobsters than at higher densities; therefore, ventless traps were saturating not because they had reached a theoretical maximum capacity but for reasons that have yet to be determined. The major goal of this investigation was to use underwater video surveillance techniques to observe and quantify the behavior of American lobsters in and around ventless and standard traps in order to gain a better understanding of the mechanisms underlying trap saturation, defined as a plateau in catch over time, in both trap types.

Video surveillance makes it possible to study animals in their natural habitats without the interference

\footnotetext{
${ }^{3}$ Estrella, B. T., and R. P. Glenn. 2006. Lobster trap escape vent selectivity. Mass. Div. Mar. Fish., Tech. Rep. TR-27, 15 p. [Available at website.]
}

of humans (Mallet and Pelletier, 2014). For example, Jury et al. (2001) attached a video recording system to a standard lobster trap and noted the behaviors of American lobsters in and around a trap for up to 48 $\mathrm{h}$. The data from that study indicated that many of the lobsters that enter traps ultimately escape. Subsequently, other investigators used similar methods to observe the behavior around traps of commercially important marine crustaceans, including the Caribbean spiny lobster (Panulirus argus; Weiss et al., 2006), Japanese rock crab (Charybdis japonica; Vazquez Archdale et al., 2007), Dungeness crab (Cancer magister; Barber and Cobb, 2009), and blue crab (Callinectes sapidus; Reichmuth et al., 2011).

Despite these advances, the mechanisms that cause saturation in crustacean traps are still not fully understood. The most generally accepted explanation is that trap saturation is due, in part, to the competitive and agonistic interactions between conspecifics inside and outside a trap (Richards et al., 1983; Miller, 1990; Addison, 1995; Jury et al., 2001; Barber and Cobb, 2009; Ovegård et al., 2011). For example, pots used to catch Dungeness crab are believed to saturate because of agonistic interactions between entering crabs and approaching crabs (Barber and Cobb, 2009). Similar territoriality has been observed in and around lobster traps (Richards et al., 1983; Addison, 1995; Jury et al., 2001). Prestocking standard traps with American lobsters caused a reduction in entry rate and therefore catch (Richards et al., 1983; Addison, 1995; Watson and Jury, 2013). These findings, combined with those of Jury et al. (2001), suggest that saturation of standard traps is at least partially a function of increased agonistic interactions between lobsters in and around traps-interactions that reduce the rate of entry as traps accumulate lobsters. However, if agonistic interactions were the only cause of saturation, then traps would be expected to reach this plateau sooner at higher densities. Clark et al. (2015) observed that the catch 


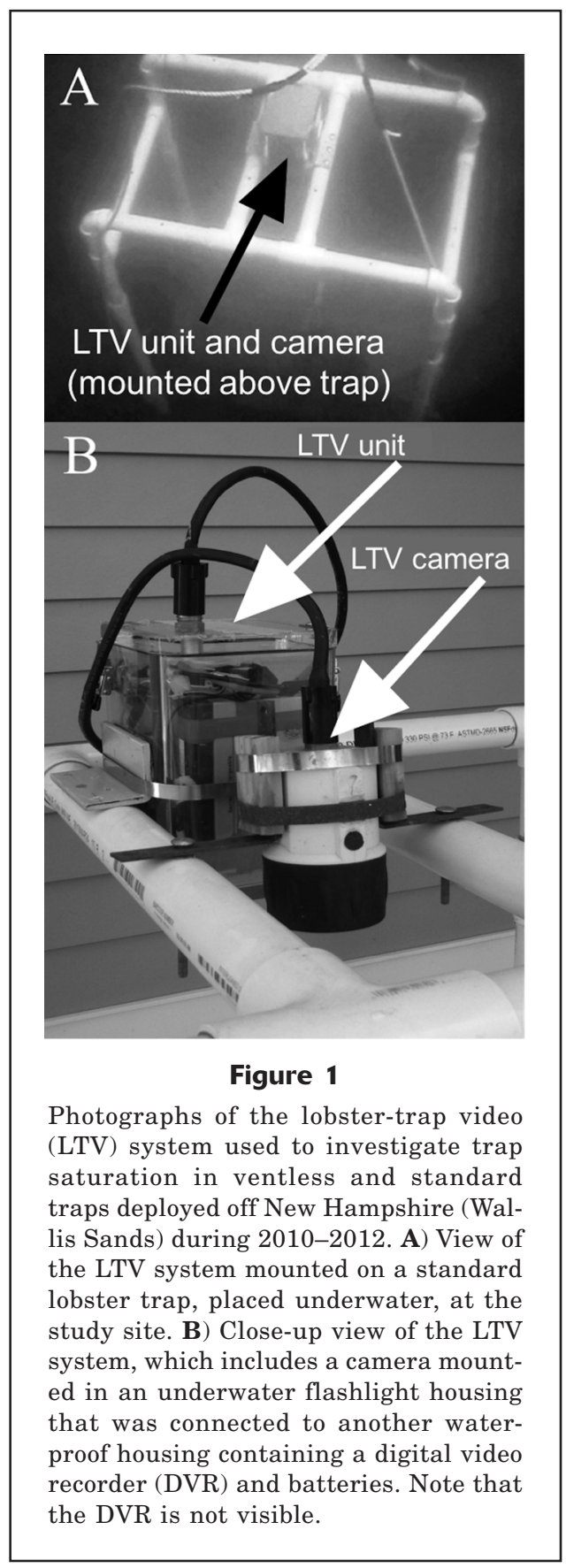

in lobster traps consistently plateaued after 16 to 24 $\mathrm{h}$ for both high and low densities of lobsters. Thus, other factors that potentially influence trap saturation in both standard and ventless traps were the focus of our study.

Our objective was to identify factors that affect the saturation of lobster traps. The behavior of American lobsters was observed by using a modification of the lobster-trap video system that had been incorporated into previous studies conducted off New Hampshire (Jury et al., 2001; Watson and Jury, 2013). We hypothesized that changes in the entry rate in relation to the escape rate over the period of a soak would cause catch in traps to plateau.

\section{Materials and methods}

\section{Study site}

All data from video surveillance of traps were collected from 2010 to 2012 at a study site $(0.8 \times 2.5 \mathrm{~km})$ just offshore of Wallis Sands State Beach in Rye, New Hampshire (for details, see Clark et al., 2015). This location was chosen because previous trap studies were conducted there to take advantage of the predominantly sandy bottom, which made it easier to obtain accurate estimates of the density of American lobsters during dive surveys and to observe lobsters around the traps by using our digital video system. Additionally, few commercial lobstermen fished in this area throughout our study.

\section{Trapping trials and dive surveys}

Between June and September of 2010-2012, 6 trials (3 with standard traps and 3 with ventless traps) were completed (Table 1). During these 6 trials, the densities of American lobsters were similar, all of the traps were deployed for $2 \mathrm{~d}$, and high-quality video recordings of lobster activity were obtained. Traps were baited at the beginning of each trial with 3-4 frozen Atlantic herring (Clupea harengus; $\geq 0.2 \mathrm{~kg}$ in total) from the same source (Little Bay Lobster Co. ${ }^{4}$, Newington, NH).

Dive surveys $(n=8)$ were performed a week before or after the 6 trapping trials to estimate densities of lobsters and to determine the size composition of the lobster population in the area fished with traps. The methods for the dive surveys are described in Clark et al. (2015). Briefly, 2 scuba divers swam along 4 transects (30-60 $\mathrm{m} \times 4-6 \mathrm{~m}$, depending on visibility), one transect in each of the cardinal directions. Before trap de[ployment, lobsters were counted to estimate lobster densities. After each trial, lobsters were collected by divers to determine size composition of the lobster population. Divers handled lobsters only during the surveys that were conducted after each trial or after the traps were hauled. Handling the lobsters before trap deployment would have potentially caused lobsters to move out of the area during the trials, a change that would, thereby, have altered the density of lobsters. The data from these surveys were converted to density estimates, as the number of individuals per square meter, for analyses. For the lobsters that were brought to the surface, carapace length (CL) and sex were recorded before the lobsters were returned to their area of capture. The mean CL of the lobsters measured during the dive surveys was $46.4 \mathrm{~mm}$ (standard error of

\footnotetext{
${ }^{4}$ The mention of trade names or commercial products throughout this article is for identification purposes only and does not imply endorsement by the National Marine Fisheries Service, NOAA.
} 


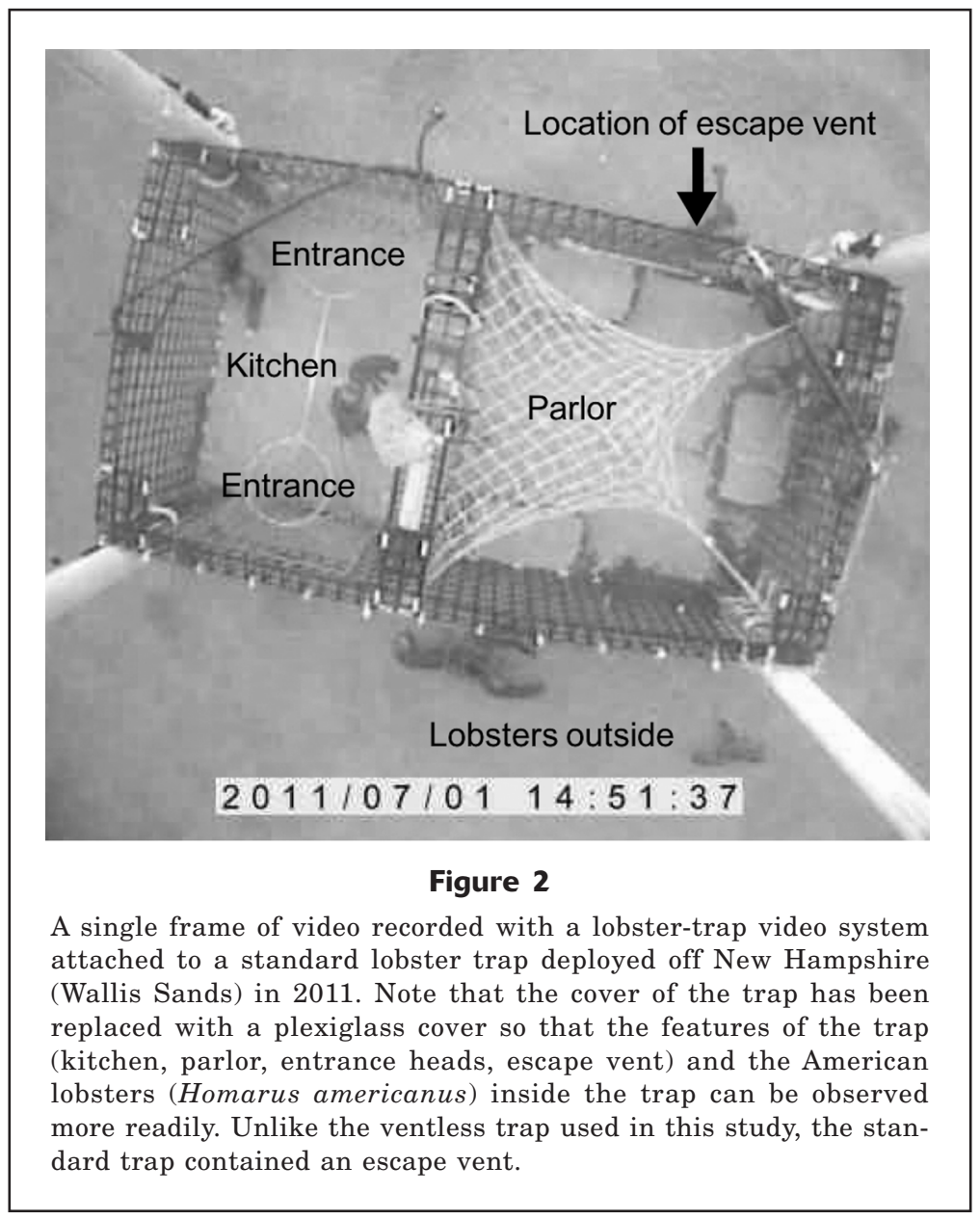

the mean [SE] 1.27), and values ranged from 25 to 160 $\mathrm{mm}$. Lobsters caught during the 6 trials in ventless traps had a mean CL of $60.2 \mathrm{~mm}$ (SE 1.14) and, of these lobsters, less than $1 \%$ were at or above the lower legal-size limit for the American lobster inshore fishery (83 $\mathrm{mm} \mathrm{CL}$ ). None exceeded the upper legal-size limit for the fishery (127 $\mathrm{mm} \mathrm{CL})$.

The 6 trials included in this study were conducted at a mean lobster density of 0.1 individuals $/ \mathrm{m}^{2}$ (SE $0.02 ; n=8)$, which was consistent between trials and relatively high for this area and season (June to September; Clark et al., 2015). The mean water temperature across the trials was $16.1^{\circ} \mathrm{C}(\mathrm{SE} 1.2)$.

\section{Trap video system}

The video system used in this study, lobster-trap video system (LTV), was modified from the original system developed by Jury et al. (2001). A fisheye bullet camera with a charge-coupled device chipset, 0.5 lux low light sensitivity, and 2.2-mm wide-view lens (Model PC221HR, Sony Corp., Tokyo, Japan) was sealed inside an underwater flashlight case and mounted on the top of a PVC frame (Fig. 1A), $122 \mathrm{~cm}$ above the trap. The camera was connected by a waterproof cable to a water-tight acrylic case containing a mini digital video recorder (DVR) with a resolution of $640 \times 480$ lines (Model UVK206, Unique Vision Technology Co., Ltd., Shenzhen, China) and encasing several $12 \mathrm{~V}$ batteries (Fig. 1B). The DVR was programmed to capture videos at a rate of 5 frames/s and was turned on at dawn and off at dusk with a digital timer to save power. Only footage collected during the daylight hours of day 1 and day 2 was included in the analyses. No data were obtained at night because rate of trap entry does not generally differ between day and night at this location (Jury et al., 2001), and the addition of lights could have influenced American lobster behaviors. Digital recordings were stored on a Secure Digital High Capacity memory card (16 GB) and transferred to a computer for analyses after each trial. The replacement of the trap lid with transparent plexiglass made it possible for viewers of video recordings to more readily observe lobsters inside of the kitchen and parlor areas of traps (Fig. 2). Digital videos were obtained for a duration of $6.7 \mathrm{~h}$ (SE 1.1) on day 1 and $9.0 \mathrm{~h}$ (SE 1.6) on day 2 (Table 1 ).

The dimensions of each standard and ventless trap are provided in Clark et al. (2015). Briefly, the wire 


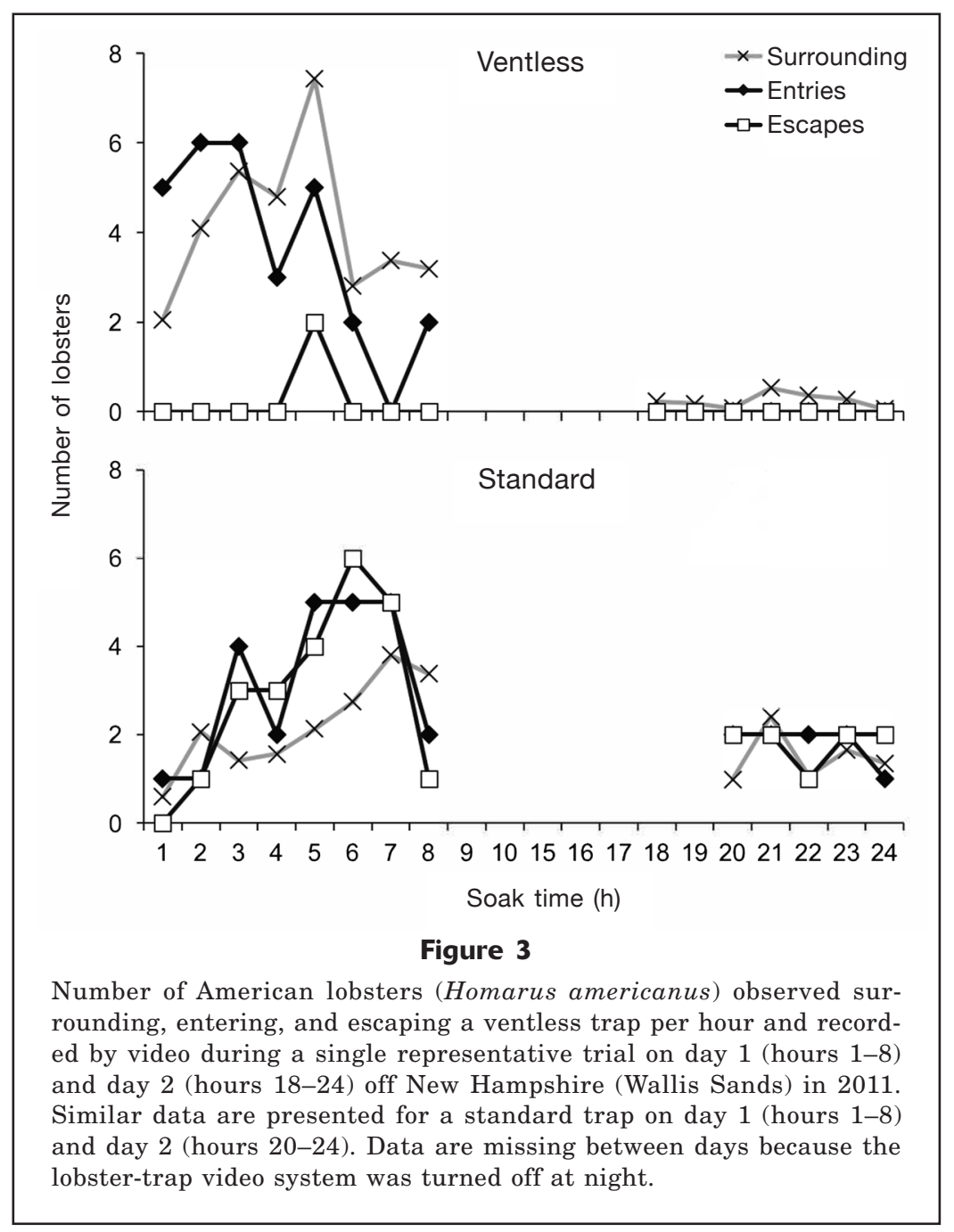

mesh for all traps was $2.5 \times 2.5 \mathrm{~cm}$ and the rectangular trap dimensions were $90 \times 47 \times 35 \mathrm{~cm}$. The kitchen of each trap contained 2 entrances, both $12.7 \mathrm{~cm}$ in diameter (Fig. 2). The parlor of each standard trap had a single escape vent $(14.6 \times 4.9 \mathrm{~cm})$; ventless traps had no escape vents.

\section{Data analysis}

To determine factors that influenced trap saturation, the following parameters were quantified for each hour of observation of video recordings: 1) the number of American lobsters entering, escaping, and surrounding the traps and 2) the accumulated catch. When lobsters entered the trap, they continued to be observed to determine whether they would enter the parlor or leave the trap (see Fig. 2). In general, lobsters could not be identified individually; therefore, if a lobster left the field of view and then returned, it was treated as a new lobster. The rates at which lobsters accumulated in traps were calculated by using linear regression analyses. The statistical analyses presented here were performed with RStudio, vers. 1.0.136 (RStudio Team, 2009). Because videos were not recorded at night, the beginning of saturation for ventless traps (between 16 and 24 h; Clark et al., 2015) was not captured; therefore, segmented linear regression analyses were used to estimate rates of accumulated entries, escapes, and catch. Each parameter (total number of lobsters entering, escaping, and surrounding traps) was compared by using a Mann-Whitney $U$ test. Only the first $3 \mathrm{~h}$ of footage recorded on day 1 and on day 2 were incorporated into the analyses because these recordings had the highest quality across all trials. For example, the total number of lobsters entering all ventless traps $(n=3)$ within the first $3 \mathrm{~h}$ on day 1 was compared with the total number of lobsters entering within the first $3 \mathrm{~h}$ on day 2 . To compare CPUE in standard and ventless traps, catch values were first transformed by using the natural log and then analyzed by using the MannWhitney $U$ test. All reported variations are standard deviations (SD) unless indicated otherwise. 
Table 2

Mean number of American lobsters entering, escaping, and surrounding each trap per hour during 6 trials in which ventless and standard traps were deployed for periods of 2 d off New Hampshire (Wallis Sands) during 2010-2012. The means and standard deviations (SD) were calculated by using data from the first $3 \mathrm{~h}$ of each day.

\begin{tabular}{|c|c|c|c|c|c|c|c|}
\hline \multirow[b]{2}{*}{ Trial } & \multirow[b]{2}{*}{ Trap type } & \multicolumn{2}{|c|}{$\begin{array}{l}\text { Number of entries } \\
\text { (SD) }\end{array}$} & \multicolumn{2}{|c|}{$\begin{array}{l}\text { Number of escapes } \\
\text { (SD) }\end{array}$} & \multicolumn{2}{|c|}{$\begin{array}{c}\text { Number of lobsters } \\
\text { surrounding traps (SD) }\end{array}$} \\
\hline & & Day 1 & Day 2 & Day 1 & Day 2 & Day 1 & Day 2 \\
\hline 1 & Standard & $4.7(2.1)$ & 0 & $4.0(2.0)$ & 0 & $3.4(1.9)$ & $3.1(0.2)$ \\
\hline 2 & Standard & $3.7(2.9)$ & $4.0(1.0)$ & $4.0(3.6)$ & $3.3(2.1)$ & $2.5(0.8)$ & $1.6(0.1)$ \\
\hline 3 & Standard & $2.0(1.7)$ & 2.0 & $1.3(1.5)$ & $1.7(0.6)$ & $1.4(0.7)$ & $1.5(0.8)$ \\
\hline 4 & Ventless & $2.7(0.6)$ & $0.3(0.6)$ & $1.0(1.7)$ & 0 & $2.2(0.6)$ & $0.3(0.1)$ \\
\hline 5 & Ventless & $5.7(3.1)$ & $1.3(1.2)$ & $1.0(1.7)$ & $0.7(0.6)$ & $3.5(0.1)$ & $0.6(0.4)$ \\
\hline 6 & Ventless & $5.7(0.6)$ & 0 & 0 & 0 & $3.8(1.7)$ & $0.2(0.1)$ \\
\hline
\end{tabular}

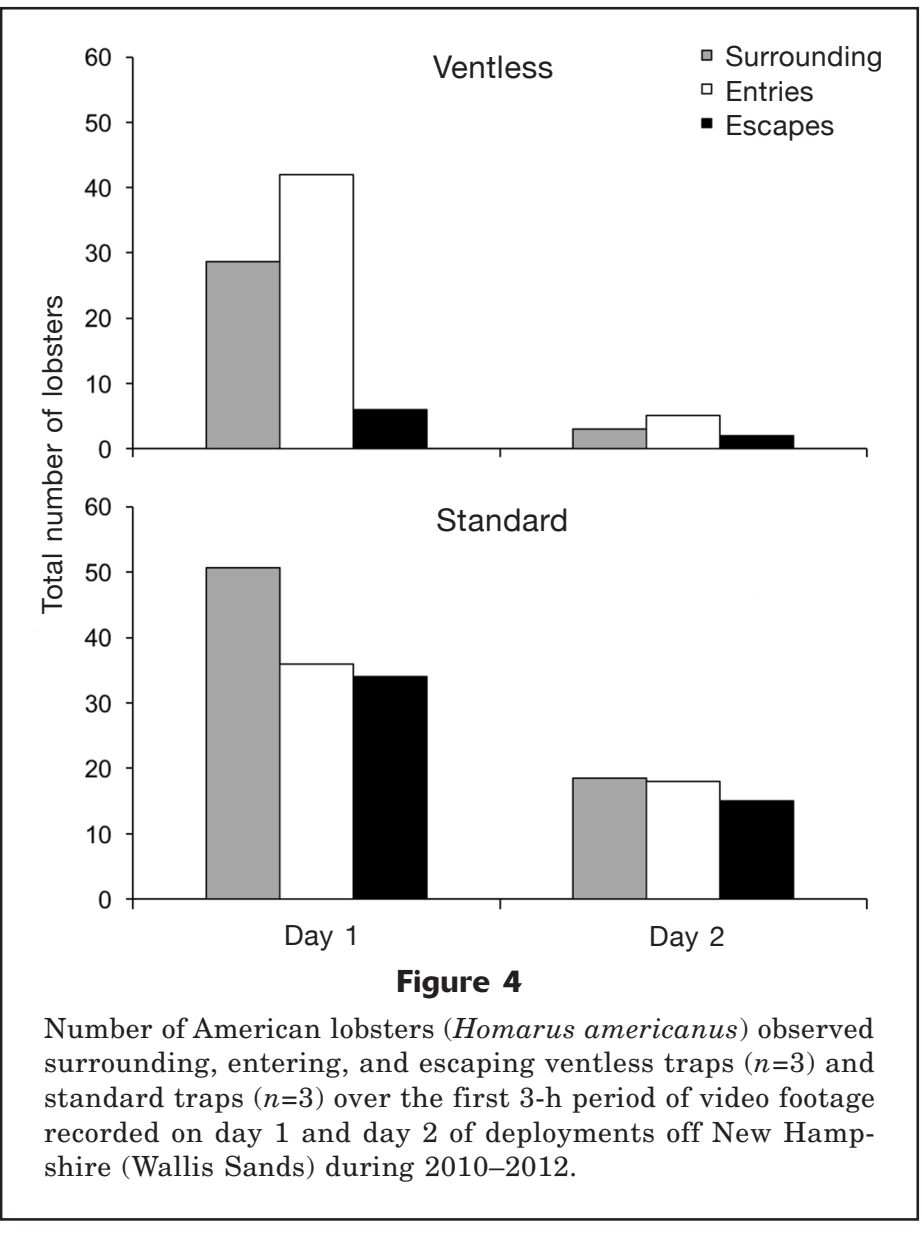

To determine whether American lobsters inside the trap inhibited the entry of approaching lobsters, halfentries, defined as any instance in which a lobster made contact with the mesh funnel of the kitchen entrance but did not fully enter the kitchen (Jury et al., 2001), were quantified. Our working hypothesis was that if the lobsters inside the trap inhibited other lob- sters from entering the trap on day 2 , the number of half-entries should be higher on day 2 than on day 1 . Because we expected more lobsters to have accumulated inside the ventless traps by day 2 , we also expected more agonistic interactions between entering lobsters and the lobsters already in the trap and, therefore, more half-entries toward the end of each trial. After calculating the total number of half-entries, we used the MannWhitney $U$ test to determine whether differences existed over time and between trap types.

\section{Results}

Movements in, and around, standard and ventless traps

A similar number of American lobsters entered ventless traps and standard traps on day 1 (Figs. 3 and 4, Table 2; Mann-Whitney $U=7$, $P>0.05)$. There was also no significant difference in the number of lobsters surrounding each trap (Mann-Whitney $U=7, P>0.05$ ). However, significantly more lobsters escaped from standard traps than from ventless traps (Mann-Whitney $U=0$, $P<0.05$ ). On day 2, a similar number of lobsters entered (Mann-Whitney $U=2.5, P>0.05$ ) and escaped (Mann-Whitney $U=2, P>0.05$ ) each respective trap type. For example, on day 2, 5 lobsters entered ventless traps and 2 escaped. Even so, there were fewer lobsters surrounding ventless traps than standard traps (Mann-Whitney $U=0$, $P<0.05)$.

Fewer lobsters entered ventless traps on day 2 than on day 1 (Figs. 3 and 4, Table 2; Mann-Whitney $U=9$, $P<0.05)$. Although there was no difference in the number of lobsters escaping from ventless traps on day 1 versus day 2 (Mann-Whitney $U=7, P>0.05$ ), significantly fewer lobsters surrounded the ventless traps on day 2 than on day 1 (Mann-Whitney $U=9, P<0.05$ ). 


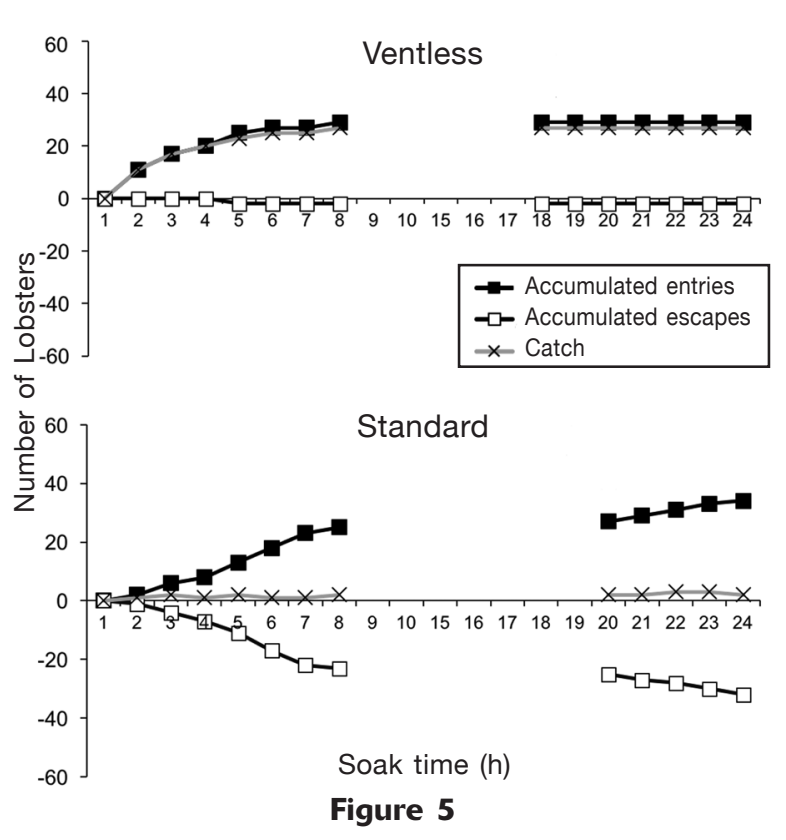

Number of entries, escapes, and catch of American lobsters (Homarus americanus) accumulated per hour during a single representative trial with a ventless trap and a single trial with a standard trap over $8 \mathrm{~h}$ on day 1 and 5-7 h on day 2 (no data were collected at night). Both traps were deployed off New Hampshire (Wallis Sands) during 2010-2012.

For standard traps, approximately the same number of lobsters entered (Mann-Whitney $U=6.5, P>0.05$ ), escaped (Mann-Whitney $U=7, P>0.05$ ), and surrounded the traps (Mann-Whitney $U=5, P>0.05$ ) throughout the 2 -d soak.

\section{Accumulated entries and escapes}

Some trap dynamics differed between day 1 and day 2 . For ventless traps, the rates of entry, escape, and catch on day 1 exceeded those observed on day 2 (Figs. 5 and 6; Mann-Whitney $U=9, P<0.05$ for all variables). For standard traps, the rates of entry, escape, and catch did not significantly differ over the 2-d soak (Mann-Whitney $U=7, P>0.05$ ). Because entry rate and exit rate were equivalent on each day, standard traps caught lobsters at similarly low rates on days 1 and 2 (Mann-Whitney $U=6, P>0.05$ ); therefore, very few, if any, lobsters were captured by the standard traps. In contrast, ventless traps had higher CPUE on day 1 than on day 2 (Mann-Whitney $U=9, P<0.05$ ). The lobsters could not easily leave the ventless traps because of the absence of an escape vent and, as a result, escape rates were lower than entry rates on day $1(\sim 1$ individual/h in contrast with 7 individuals/h, respectively). Ventless traps continued to accumulate lobsters until catch plateaued on day 2 (Fig. 5). At the end of each trial, ventless traps had higher CPUE than standard traps (Fig. 7; Mann-Whitney $U=9, P<0.05$ ).
Comparison of half-entries on days 1 and 2 of the soak period

A similar number of half-entries took place in the 2 types of traps on day 1 (Fig. 7; Mann-Whitney $U=5$, $P>0.05$ ) and on day 2 (Mann-Whitney $U=4.5, P>0.05$ ). Moreover, there was a higher frequency of half-entries on day 1 than on day 2 for standard and ventless traps (Mann-Whitney $U=9, P<0.05$ ).

While quantifying half-entries, we identified the following types of deterrents to entrapping American lobsters: 1) disturbance of entering lobsters by approaching conspecifics; 2) agonistic interactions of approaching lobsters with lobsters that were already inside the trap; 3) current-induced movements of the bait bag that potentially startled lobsters; and 4) apparent loss of interest of approaching lobsters (cause unknown). Deterrents for half-entries were classified as unknown if a lobster approached the trap, usually making contact with it, but left without any obvious cause. Unlike lobsters that exhibited a half-entry for one of the reasons listed above, the lobsters that half-entered for no apparent reason rarely exhibited an avoidance response (i.e., tail-flipping) before leaving the field of view. In both types of traps, half-entries occurred predominantly because of either loss of interest (unknown) or intimidation by approaching lobsters. Loss of interest was responsible for $43 \%$ and $55 \%$ of the half-entries observed in ventless and standard traps, respectively, and intimidation by approaching lobsters accounted for almost $30 \%$ of the half-entries in each trap type. Agonistic interactions with lobsters inside of ventless and standard traps were responsible for $18 \%$ and $11 \%$ of the half-entries, respectively. The movement of bait bags within each trap had the least effect, causing $<10 \%$ of the half-entries.

\section{Discussion}

The results from this set of experiments provide insight into the mechanisms that are likely responsible for the saturation of lobster traps, particularly ventless traps. For example, catch of American lobsters in ventless traps reached a plateau on day 2 of a soak owing, in part, to a reduction in the rate at which lobsters entered the traps. The data illustrated in Figures 3 and 5 indicate that this leveling off of entry rate may be due, at least partly, to a decrease in the density of lobsters in the vicinity of the trap. This decrease in the number of lobsters surrounding traps may have occurred because ventless traps accumulated so many lobsters that they effectively reduced the local density of lobsters. However, in a more recent study (W. Watson, unpubl. data), the results of dive surveys that corresponded with trap trials indicate that the number of lobsters in the fishable area did not change between day 1 and day 2; therefore, we hypothesize that other factors, such as loss of bait attractiveness after approximately $24 \mathrm{~h}$, may be the reason that fewer lobsters approached and entered both types of traps on day 2 versus day 1 . 


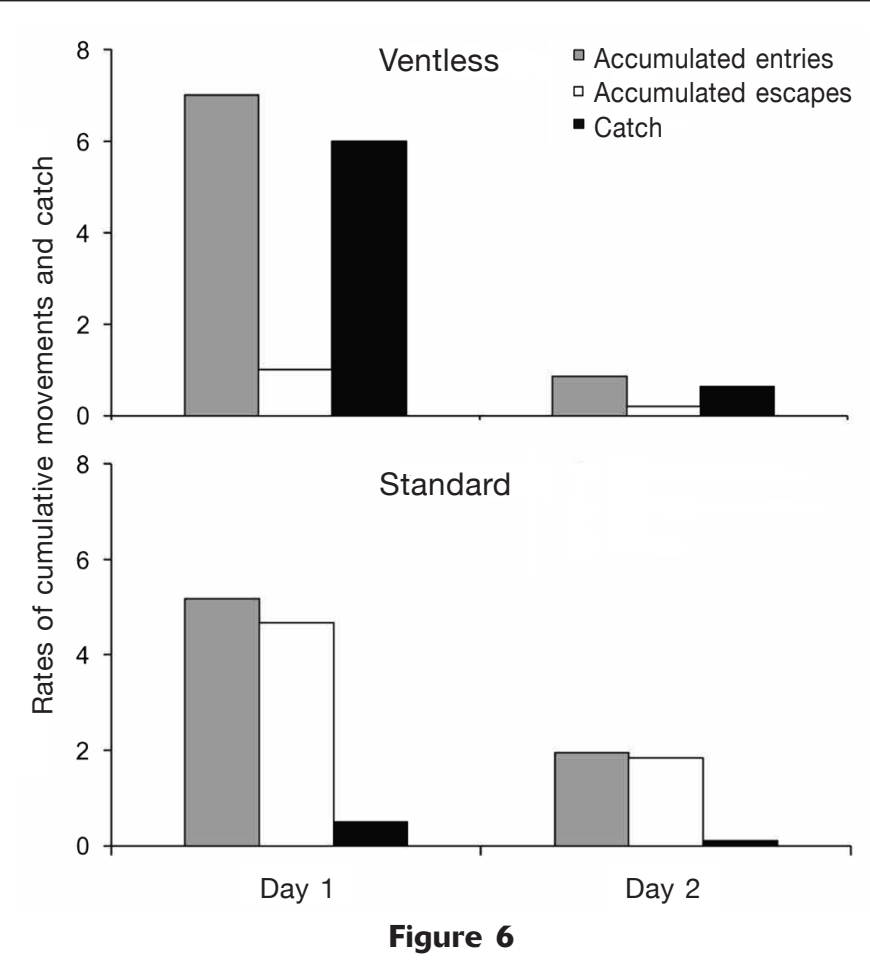

Rates at which entries, escapes, and catch of American lobsters (Homarus americanus) accumulated in ventless traps $(n=3)$ and standard traps $(n=3)$ over the first 3 -h period on day 1 and day 2 of deployments off New Hampshire (Wallis Sands) during 2010-2012. Rates were calculated by using the slopes of the regression lines fitted to each segment of data points. sters and some crab species (e.g., Cancer spp.). A more recent study has provided evidence that prestocking reduces the rate of entry, but it does not reduce the total catch in standard traps if the total catch includes the stocked lobsters (Watson and Jury, 2013). However, it should also be noted that, in general, traps in most of the previous studies were stocked with adult, legal-size lobsters, but in this study, many of the lobsters observed in and around the traps were of sublegal size. Interestingly, in our study, interactions with lobsters inside the traps did not appear to be the dominant cause of half-entries. Rather, disturbance by lobsters outside of the traps accounted for almost $30 \%$ of half-entries for each trap type. When the lobsters approached the traps, other encroaching lobsters outside of the traps often deterred their conspecifics from entering by lunging at them or chasing them away from the trap entrances. This type of behavior was observed around both standard and ventless traps and limited the frequency of successful entries into each trap type. Even when there were lobsters inside the kitchen, entry rates were influenced more by interactions outside of the traps and, therefore, by the density of lobsters around the traps.

Most lobsters in ventless traps accumulated in the parlor area of traps, rather than the kitchen, and it is unlikely that they directly influenced subsequent trap entries unless there were other deterrent cues provided by trapped lobsters (e.g., olfactory cues, auditory cues). Importantly, with regard to the mechanisms that lead to catch leveling off at some value, there were fewer halfentries on day 2 , for both trap types, than on day 1 (Fig. 7); therefore, agonistic interactions between lobsters inside and outside of the traps may have contributed to the reduction in trap entries, as observed in previous studies, but they were likely not the reason entries and catch leveled off on day 2 .

The decline in lobsters outside of the ventless traps on day 1 was negatively correlated with the number of lobsters inside the traps. However, because the lobsters were not tagged, it was not possible to track the movement of individuals; therefore, we cannot conclude that lobsters in the surrounding field of view at the point of trap deployment were, in fact, the same lobsters that were caught later in the trial. Nonetheless, the relationship between increasing catch by ventless traps and decreasing number of surrounding lobsters (observed) indicates that these lobsters are partially removed from the fishable area of the trap. On the other hand, the number of lobsters that surrounded standard traps did not significantly differ between day 1 and day 2. This difference between trap types may have been a result of the size-frequency distribution of lobsters in this area-a distribution over which most of the lobsters (>99\%) were below legal size (as determined by using data from dive surveys). Because of

their size, many lobsters were able to exit through the their conspecifics. Richards et al. (1983) showed that prestocking traps inhibits the catch of additional lob- 
escape vents in standard traps (Nulk, 1978; Saila et al., 2002; Courchene and Stokesbury, 2011), and some of them likely remained in the vicinity of the traps.

\section{Entry and escape rates}

The rate of American lobster entries and escapes varied between the 2 types of traps. For standard traps, lobsters entered and escaped at approximately the same rates each day (Figs. 5 and 6 ), resulting in an overall low catch when traps were hauled on day 2 . In standard traps, when a lobster entered through the kitchen entrance, it would either escape through the entrance or move into the parlor (Fig. 2). As observed by Karnofsky and Price (1989), lobsters often escaped the parlor shortly after entering it ( $<2 \mathrm{~min})$. Similarly, in our study, standard traps did not saturate because, once a lobster entered the trap, that same lobster, or one of the other lobsters already in the trap, left shortly thereafter.

Ventless traps filled with lobsters at a rate of $\sim 7$ individuals/h on day 1 , but the rate of entry by day 2 slowed to about $12 \%$ of the rate of day 1. Because very few lobsters escaped from the ventless traps, a relatively high number of lobsters accumulated in ventless traps on day 1 and an average of 23 individuals (SD 7.8) remained in the trap until the end of the 2-d soak (Table 1, Figs. 5-7). The mean density of lobsters during trap deployment was 0.1 individuals $/ \mathrm{m}^{2}$ (SD 0.02). Assuming that a typical effective fishing area around a trap is deployed for a 24-h soak is $2600 \mathrm{~m}^{2}$ (Watson et al., 2009), there would be a pool of 260 lobsters $\left(0.1\right.$ individuals $\left./ \mathrm{m}^{2} \times 2600 \mathrm{~m}^{2}\right)$ that might approach or encounter a trap in day 1 . Fewer than 260 lobsters approached the ventless trap in each trial of this study; therefore, it is unlikely that ventless traps saturated from catching all of the available lobsters. Our data do not support the hypothesis that depletion, or reduction, in the number of lobsters within the effective fishing area is a primary cause of trap saturation.

Approximately $40-50 \%$ of the bait, determined by weight, remained in ventless traps after having soaked for $24-48$ h (Clark, 2012). Interestingly, ventless traps retained more bait by weight than standard traps after $48 \mathrm{~h}$, possibly because lobsters repeatedly escaped and re-entered the standard traps to consume the remaining bait (Clark, 2012; Clark et al., 2015). However, even though bait remained, the olfactory attractiveness of the bait likely declined after a 24-h soak, as a result of the leaching of attractants (W. Watson, unpubl. data). We hypothesize that because typical lobster bait releases more odorants early in the soak time (i.e., $<24 \mathrm{~h}$ ), the rate of entry into traps eventually declines and an equilibrium between entries and escapes is reached, leading to a plateau in catch level and trap saturation.

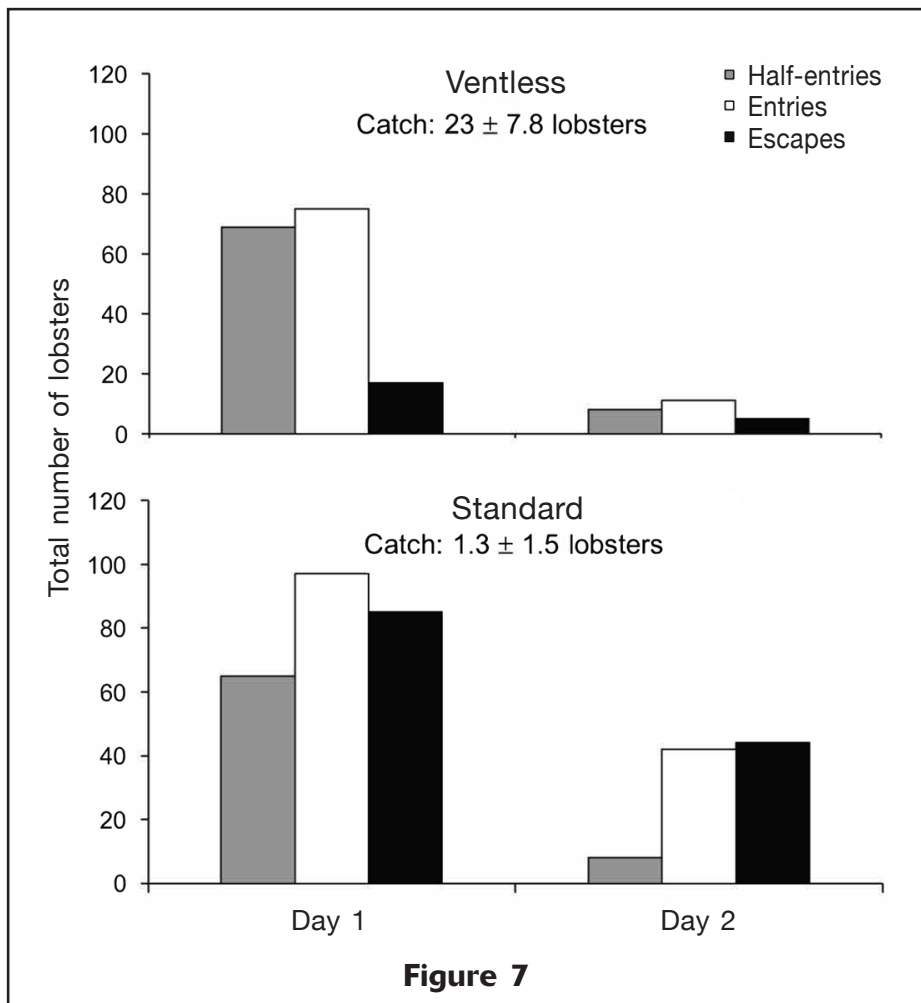

Number of half-entries, entries, and escapes of American lobsters (Homarus americanus) in ventless traps $(n=3)$ and standard traps $(n=3)$ during the first 3 -h period on day 1 and day 2 of deployments off New Hampshire (Wallis Sands) during 2010-2012. Catch values represent the mean number of lobsters caught in ventless traps and standard traps after each trial, determined by cumulative number of entries and escapes (Table 1, Fig. 6). A half-entry is an instance when a lobster makes contact with the mesh funnel of a kitchen entrance in a trap but does not fully enter the kitchen.

\section{Acknowledgments}

We recognize the support of the state fisheries agencies and the University of New Hampshire (UNH). We thank R. Glenn and T. Pugh from the Massachusetts Division of Marine Fisheries for supplying lobster traps, D. Shay and the late N. Carlson of the UNH Marine Program for their time and field assistance, UNH students K. Jenks, E. Dubofsky, H. Cheng, E. Morrissey, A. Campbell, S. LaChance, and C. Chambers for their help, and 3 anonymous reviewers for their feedback. New Hampshire Sea Grant provided funding for this research (R/CFR-15).

\section{Literature cited}

Addison, J. T.

1995. Influence of behavioural interactions on lobster distribution and abundance as inferred from pot-caught samples. ICES Mar. Sci. Symp. 199:294-300. 
Barber, J. S., and J. S. Cobb.

2009. Qualitative observations of Dungeness crabs, Cancer magister, in and around traps: evidence of resource guarding and clustering. Mar. Freshw. Behav. Physiol. 42:135-146. Article

Bergshoeff, J. A. C. H. McKenzie, K. Best, N. Zargarpour, and

B. Favaro.

2018. Using underwater video to evaluate the performance of the Fukui trap as a mitigation tool for the invasive European green crab (Carinus maenas) in Newfoundland, Canada PeerJ 6:e4223 Article

Brander, K.

2010. Impacts of climate change on fisheries. J. Mar. Syst. 79:389-402. Article

Caddy, J. F.

2004. Current usage of fisheries indicators and reference points, and their potential application to management of fisheries for marine invertebrates. Can. J. Fish. Aquat. Sci. 61:1307-1324. Article

Clark, A. S.

2012. A comparison of standard and ventless American lobster trap dynamics. M.S. thesis, 81 p. Univ. New Hampshire, Durham, NH.

Clark, A. S., S. H. Jury, J. S. Goldstein, T. G. Langley, and W. H. Watson III.

2015. A comparison of American lobster size structure and abundance using standard and ventless traps. Fish. Res. 167:243-251. Article

Courchene, B., and K. D. E. Stokesbury.

2011. Comparison of vented and ventless trap catches of American lobster with scuba transect surveys. J. Shellfish Res. 30:389-401. Article

Frusher, S. D., and J. M. Hoenig.

2001. Impact of lobster size on selectivity of traps for southern rock lobster (Jasus edwardsii). Can. J. Fish. Aquat. Sci. 58:2482-2489. Article

Ihde, T. F., S. D. Frusher, and J. M. Hoenig.

2006. Do large rock lobsters inhibit smaller ones from entering traps? A field experiment. Mar. Freshw. Res. 57:665-674. Article

Jury, S. H., H. Howell, D. F. O'Grady, and W. H. Watson III.

2001. Lobster trap video: in situ video surveillance of the behavior of Homarus americanus in and around traps. Mar. Freshw. Res. 52:1125-1132. Article

Karnofsky, E. B., and H. J. Price.

1989. Behavioural response of lobster Homarus americanus to traps. Can. J. Fish. Aquat. Sci. 46:1625-1632. Article

Mallet, D., and D. Pelletier.

2014. Underwater video techniques for observing coastal marine biodiversity: a review of sixty years of publication (1952-2012). Fish. Res. 154:44-62. Article

Miller, R. J.

1979. Saturation of crab traps: reduced entry and escapement. ICES J. Mar. Sci. 38:338-345. Article

1990. Effectiveness of crab and lobster traps. Can. J. Fish. Aquat. Sci. 47:1228-1251. Article

Nulk, V. E.

1978. The effects of different escape vents on the selectivity of lobster traps. Mar. Fish. Rev. 40(5-6):50-58.

Ovegård, M., S. Königson, A. Persson, and S. G. Lunneryd.

2011. Size selective capture of Atlantic cod (Gadus morhua) in floating pots. Fish. Res. 107:239-244. Article
RStudio Team.

2009. RStudio: integrated development for R. RStudio, Inc., Boston, MA. [Available from website.]

Reichmuth, J. M., J. MacDonald, J. Ramirez, and J. S. Weis. 2011. Fight or flight: an investigation of aggressive behavior and predator avoidance in two populations of blue crabs (Callinectes sapidus, Rathbun) in New Jersey. Hydrobiologia 658:173-182. Article

Richards, R. A., J. S. Cobb, and M. J. Fogarty.

1983. Effects of behavioral interactions on the catchability of American lobster, Homarus americanus, and two species of Cancer crab. Fish. Bull. 81:51-60.

Robertson, W. D.

1989. Factors affecting catches of the crab Scylla serrata (Forskål) (Decapoda: Portunidae) in baited traps: soak time, time of day and accessibility of the bait. Estuar. Coast. Shelf Sci. 29:161-170. Article

Rutishauser, R. L., A. C. Basu, S. I. Cromarty, and E. A. Kravitz.

2004. Long-term consequences of agonistic interactions between socially naïve juvenile American lobsters (Homarus americanus). Biol. Bull. 207:183-187. Article

Saila, S. B., S. W. Nixon, and C. A. Oviatt.

2002. Does lobster trap bait influence the Maine inshore trap fishery? North Am. J. Fish. Manage. 22:602-605. Article

Steneck, R. S.

2006. Possible demographic consequences of intraspecific shelter competition among American lobsters. J. Crustac. Biol. 26:628-638. Article

Tamm, G. R., and J. S. Cobb.

1978. Behavior and the crustacean molt cycle: changes in aggression of Homarus americanus. Science 200:79-81. Article

Vazquez Archdale, M., C. P. Añasco, Y. Kawamura, and S. Tomiki.

2007. Effect of two collapsible pot designs on escape rate and behavior of the invasive swimming crabs Charybdis japonica and Portunus pelagicus. Fish. Res. 85:202-209. Article

Watson, W., and S. H. Jury.

2013. The relationship between American lobster catch, entry rate into traps and density. Mar. Biol. Res. 9:59-68. Article

Watson, W. H., III, W. Golet, D. Scopel, and S. Jury.

2009. Use of ultrasonic telemetry to determine the area of bait influence and trapping area of American lobster, Homarus americanus, traps. N. Z. J. Mar. Freshw. Res. 43:411-418. Article

Weiss, H. M., E. Lozano-Álvarez, P. Briones-Fourzán, and F. Negrete-Soto.

2006. Using red light with fixed-site video cameras to study the behavior of the spiny lobster, Panulirus argus, and associated animals at night and inside their shelters. Mar. Technol. Soc. J. 40:86-95. Article

Williams, P. J., T. A. Floyd, and M. A. Rossong.

2006. Agonistic interactions between invasive green crabs, Carcinus maenas (Linnaeus), and sub-adult American lobsters, Homarus americanus (Milne Edwards). J. Exp. Mar. Biol. Ecol. 329:66-74. Article

Williams, P. J., C. MacSween, and M. Rossong.

2009. Competition between invasive green crab (Carcinus maenas) and American lobster (Homarus americanus). N. Z. J. Mar. Freshw. Res. 43:29-33. Article 